\title{
CORRECTION
}

\section{Correction to: A novel adaptive clustering ensemble method}

Tahani Alqurashi $^{1} \cdot$ Wenjia Wang $^{1}$

Published online: 23 March 2018

c) Springer-Verlag GmbH Germany, part of Springer Nature 2018

\section{Correction to:}

International Journal of Machine Learning and Cybernetics https://doi.org/10.1007/s13042-017-0756-7

In the original publication of the article, the article title "Clustering Ensemble Method" has been published incorrectly. The correct article title should read as "A Novel Adaptive Clustering Ensemble Method".

The original article can be found online at https://doi.org/10.1007/ s13042-017-0756-7.

Tahani Alqurashi

toand2@hotmail.com

Wenjia Wang

wenja.wang@uea.ac.uk

1 School of Computing Science, University of East Anglia, Norwich Research Park, Norfolk, UK 